\title{
Bestiario ciberpunk: sobre el imbunche y otros monstruos en Ygdrasil de Jorge Baradit $^{*}$
}

\section{Cyberpunk Bestiary: About the Imbunche and other Monsters in Ygdrasil by Jorge Baradit}

\author{
Macarena Areco \\ Pontificia Universidad Católica de Chile \\ mareco@uc.cl
}

Resumen - En el presente trabajo se analiza la representación del imbunche, junto a otros seres fragmentados o simbióticos que aparecen en la novela de Jorge Baradit, Ygdrasil (2005), como modos de imaginar las subjetividades. Ello se debe a que uno de los personajes más importantes del relato es el líder religioso sindical de una megacorporación global llamado el Imbunche, lo cual entrega una pista de lectura para buscar las características del monstruo en los restantes personajes. Este análisis nos permite concluir que esa figura muestra nuevamente su productividad, al servirle a Baradit para representar al sujeto esclavizado en el capitalismo tardío y en particular a aquel que, por estar conectado a redes informáticas, está expuesto a la colonización de su cuerpo por la biotecnología y la informática.

Palabras clave: sujeto, imbunche, fragmentación, ciencia ficción, ciberpunk.

Abstract - The following paper analyzes the representation of the imbunche, as well as other fragmented or symbiotic beings that are present in the novel Ygdrasil (2005) by Jorge Baradit, as a manner of imagining subjectivities. One of the most important characters of this novel is the religious and syndical leader of a global megacorporation named "el Imbunche", from which we can find readings to look for characteristics of monstrosity in the rest of the characters of the novel. This analysis will allow us to conclude that this figure portrays, once more, Baradit's productivity, since he uses this strategy to represent the enslaved subject in late Capitalism, especially the one that, connected to computer networks, is exposed to the colonization of the body regarding informatics and biotechnology.

Keywords: subject, imbunche, fragmentation, science fiction, cyberpunk.

* Este artículo forma parte del proyecto Fondecyt Posdoctorado $N^{\circ} 3080043$, «Tramas e imaginarios sociales en la ciencia ficción chilena reciente». 
Como una muestra más de su productiva trayectoria en el imaginario literario chileno, la figura del imbunche (aquel monstruo que, según la variante más conocida, fue en su origen un niño a quien los brujos raptaron para luego proceder a coserle los distintos orificios del cuerpo) reaparece en la novela de ciencia ficción Ygdrasil (2005), de Jorge Baradit, en el nombre de uno de sus personajes principales, el presidente del sindicato de los navegantes hiperespaciales de la transnacional Chrysler, un político inescrupuloso y sádico, que ha devenido líder de una secta de fanáticos religiosos.

Este trabajo pretende analizar las características del imbunche de Baradit, así como de algunos de los otros tipos de seres humanos híbridos que pueblan el relato, como indicios de las formas de imaginar las subjetividades en la última década. Para ello, en primer lugar esbozamos muy brevemente los principales rasgos del imbunche tal como aparece en la mitología y en la literatura chilena, así como algunos de los significados que se le han asignado como metáfora privilegiada de la identidad nacional; luego describimos al mencionado líder religioso junto a otras de las figuras que conforman el bestiario de la obra, para terminar concluyendo respecto a las modalidades subjetivas que ellas expresarían.

Como novela cercana al ciberpunk, en su bestiario Ygdrasil da cuenta de subjetividades poshumanas vinculadas a las nuevas tecnologías informáticas. Así, en este caso, las yuxtaposiciones mitológicas más acostumbradas de seres humanos con animales se alternan con las de cuerpos, órganos, partes, objetos inanimados e incluso espíritus articulados entre sí y, a su vez, conectados a redes de datos en el ciberespacio. Si bien esa mezcla de alta tecnología con animismo en una variante latinoamericana ha sido rotulada como ciberchamanismo ${ }^{1}$, preferimos denominarla ciberpunk, porque, además de los numerosos rasgos que tiene en común con esa modalidad surgida en los años ochenta, coincide con su representación ambigua de la tecnología, como liberación que deviene esclavitud, y con su figuración del sujeto sometido a grandes corporaciones mundiales que ejercen un dominio absoluto ${ }^{2}$. Creemos que, en este marco, las menciones al animismo y a mitos latinoamericanos realizadas por Baradit (por lo demás siempre desplazadas, como veremos en el caso del imbunche) están subordinadas al enjuiciamiento del capitalismo tardío, denunciado como un sistema de esclavización global.

Esta fórmula fue acuñada por Miquel Barceló, editor de la colección Nova de Ediciones B.

2 El ciberpunk es una modalidad que mezcla elementos de la novela policial de aventura con la ciencia ficción, en la que aparece por primera vez el ciberespacio. El orden mundial que describe es el del capitalismo tardío, liderado por grandes corporaciones globales y saturado por la tecnología y sus desechos. En él los seres humanos portan todo tipo de prótesis e implantes, que les permiten modificar sus cuerpos y conectarse a las redes informáticas. El protagonista, un "cowboy de consola», marginal y degradado al modo del detective de la serie negra, intenta interferir con el poder globalizado. De acuerdo a Luckhurst, se trata de un género híbrido y ambiguo, lo cual se refleja ya en su nombre, que mezcla la tecnología, lo cyber, con el margen y la anarquía, lo punk. En Ygdrasil el ciberpunk está mezclado con el splatterpunk - término acuñado en 1986 por David Schow-, un tipo de relato que incluye agresividad explícita, torturas, violaciones, desmembramientos, derrames de órganos y fluidos, etc. 


\section{EL IMBUNCHE}

Citando diversas fuentes, la antropóloga Sonia Montecino señala que «imbunche» es una palabra mapudungún ${ }^{3}$, que significa cuadrúpedo pequeño, enano o monstruo y que se usa para referir, en el imaginario mapuche y chilote, al niño raptado por los brujos para que resguarde sus cuevas, el cual:

sufre deformaciones y torturas que lo convierten en una mezcla de humano y animal. En primer lugar los brujos le quiebran la pierna izquierda y se la adosan a la espalda [...], por lo que camina dando brincos; luego le tuercen la cabeza hasta darla vuelta [...] para despistar a los intrusos [...] También se sabe que se le obstruyen todos los orificios del cuerpo, excepto la boca (245).

El ser resultante de estas operaciones es alimentado con leche de gata o cabra negra, carne de chivo o, según otros, de angelito, y no habla, debido a que le parten la lengua en dos y a que ha sido criado solo en una cueva, por lo que no aprende el lenguaje humano.

En la tradición literaria chilena el imbunche ha tenido un lugar prominente. La mención más antigua de que tenemos noticia aparece en la novela Don Guillermo (1860), de José Victorino Lastarria. En ella el protagonista, Guillermo Livingston, es capturado por un monstruo porteño, El Chivato, frente a su cueva en Valparaíso, después de lo cual se sumerge en una república infernal llamada Espelunco ${ }^{4}$, donde apenas escapa de ser sometido al imbunchaje. Así lo relata Lastarria:

La población entera de Valparaíso sabe que, en la época a que nos referimos, había dado a la cueva su nombre y mucha celebridad cierto chivato monstruoso que por la noche salía de ella para atrapar a cuantos por allí pasaban. Es fama que nadie podía resistir a las fuerzas hercúleas de aquel feroz animal, y que todos los que caían en sus cuernos eran zampuzados en los antros de la cueva, donde los volvía imbunches, si no querían correr ciertos riesgos para llegar a desencantar a una dama que el chivo tenía encantada en lo más apartado de su vivienda (41).

Otra referencia importante se encuentra en Mitópolis de Joaquín Edwards Bello ${ }^{5}$, en una de cuyas crónicas se lee que el imbunchismo, un procedimiento atribuido por el escritor a brujos mapuches, consiste en «robar niños hermosos y bien conformados para deformarlos monstruosamente» (39). El autor de El roto, quien publica el artículo en 1959 con motivo de la destrucción de una escultura de un niño de Rebeca Matte, opina que es ésta una industria que ha perdurado en el Chile moderno y que consiste en una "reacción de la envidia» (40) y una manifestación del «espíritu de destrucción», «jactancia por la fealdad» y el desprecio por "ciertas formas de belleza humana» que caracteriza a sus compatriotas y a sus vecinos. "Todos los suramericanos», dice, "vivimos en escenarios fatalmente empequeñecedores, los cuales tienden a aplastar lo sobresaliente» (14). Edwards Bello entiende el imbunchismo como una clave de lectura de la identidad nacional que se proyecta al presente: «El invunche sobrevive en forma de deformaciones morales, en

3 Según Edwards Bello, la palabra <invunche` es originaria de la lengua veliche, de los chilotes, que aún es hablada por algunos ancianos de las islas Apiao, Alao y Chaulinecy. Proviene de las voces «ivún`, pequeño ser, y «che`, hombre; es decir, significa, hombrecillo (43).

4 Espelunco es un anagrama de pelucones, nombre que se daba a los conservadores chilenos.

5 Se trata de una recopilación de crónicas publicada por Alfonso Calderón en 1973. 
tergiversaciones de hechos referentes a personas y en el acto de degenerar o de viciar las leyes y las costumbres europeas al poco tiempo de haberlas adaptado a nuestro modo de vivir» $(14-5)^{6}$.

Más conocida que todas las anteriores es la exposición de este mito en El obsceno pájaro de la noche — quizás la novela más ambiciosa de José Donoso-, donde el narrador, el Mudito, es imbunchado:

Me meten adentro del saco. Las cuatro se arrodillan alrededor mío y cosen el saco. No veo. Soy ciego. Y otras se acercan con otro saco y me vuelven a coser [...] y siento levantarse alrededor mío otro envoltorio de oscuridad, otra capa de silencio que atenúa las voces que apenas distingo, sordo, ciego, mudo, paquetito sin sexo, todo cosido y atado con tiras y cordeles, sacos y más sacos [...] aquí adentro se está caliente, no hay necesidad de moverse, no necesito nada (374-75).

Del proceso de imbunchaje, Donoso enfatiza la represión sexual, cercana a la castración, como se percibe en una descripción anterior, cuando las viejas fajan al Mudito para convertirlo en la guagua de la Iris:

Comienzan a envolverme, fajándome con vendas hechas de tiras de trapo. Los pies amarrados. Luego me amarran las piernas para que no pueda moverlas. Cuando llegan a mi sexo lo amarran como si fuera un animal dañino, como si adivinaran a pesar de su disfraz infantil que yo lo controlo, no se vaya a saber lo que oculto, y me fajan el sexo amarrándomelo a un muslo para anularlo. Luego me meten a una especie de saco, con los brazos fajados a las costillas, y me amarran en una humita que solo deja la cabeza afuera $(263)^{7}$.

Destacamos este énfasis precisamente porque no coincide con la representación que hace Baradit del Imbunche, el cual es un sujeto altamente erotizado, según mostraremos más adelante.

En su ensayo La muralla enterrada, Carlos Franz considera al imbunche «la forma nacional favorita» (19). Según el escritor, los tajamares del río Mapocho, construidos a fines de la Colonia, enterrados gran parte del siglo XX y que fueron apareciendo en el verano de 1975 por las obras de construcción del Metro, serían el «síntoma y símbolo de nuestra identidad 〈imbunchada» (19): «Torvo, tullido, desmembrado, todavía escurriendo la sangre seca de sus mutilaciones, el muro me pareció ahora la imagen mayúscula de uno de esos imbunches de nuestra mitología» (18).

En una línea similar a Edwards Bello, Franz relaciona esa imagen con «nuestros atavismos» (18), a los cuales somos fieles «mutilando y cortando, pero también zurciendo y parchando» (18-9). En síntesis, para él la muralla expresa nuestras «señas de identidad», que se resumen en el olvido de la historia, en las barreras que se esconden y en «nuestra fatal tendencia al imbunche», es decir, «la inclinación a cortar las alas de lo que se eleva [...] [a] mutilar lo que sobresale» (19). A partir de esta descripción a la vez esencialista

$6 \quad$ Nosotros podemos leer, a su vez, como punto ciego en esta mirada, el europeísmo de Edwards Bello, quien escribe desde la «mente culta de ahora» (39) y atribuye esta práctica «bárbara» y «monstruosa» a miembros de la «raza india» (19), «brujos mapuches o araucanos» (39), la cual degenera normas y costumbres europeas tenidas por correctas.

7 Antes, en el capítulo dos, se ha relatado la conseja según la cual las brujas se roban a los niños «para coserle los nueve orificios del cuerpo y transformarlos en imbunche, porque para eso, para transformarlos en imbunches, se roban las brujas a los pobres inocentes y los guardan en sus salamancas debajo de la tierra, con los ojos cosidos, el sexo cosido, el culo cosido, la boca, las narices, los oídos, todo cosido" (98). 
y fatalista, el autor opina que la ciudad de Santiago se debate «entre la muralla y el imbunche. Entre la inútil defensa de nuestras debilidades y la mutilación de nuestras posibilidades» $(19)^{8}$.

Inscribiéndose en la tradición que hemos intentado esbozar, la cual percibe a este ser mitológico como metáfora de rasgos «esenciales» de la identidad nacional, Jorge Baradit llama al perverso líder sindical de su novela el Imbunche; no obstante lo cual y a pesar de su nombre, al menos en primera instancia el personaje no posee los rasgos definitorios del monstruo. Así, sus sentidos están abiertos al mundo, lo que se expresa en su sexualidad exacerbada, representación lejana a la de Donoso9. En cambio, el Imbunche de Ygdrasil no se reprime con sus jóvenes y bellos secretarios, a los cuales no sólo somete soberanamente a sus deseos, sino que termina torturando y matando. Por otra parte, a pesar de poseer la lengua bífida, rasgo propio del imbunche y que debería impedirle hablar, el líder sindical es un gran orador, cuyo "discurso apasionado e incendiario» (74) genera el culto de la Sección 14 de la Chrysler y la guerra santa contra el directorio de la corporación. Pero, más que todo lo anterior, el personaje de Baradit es una suerte de artista de vanguardia, que se expresa con su cuerpo al modo de un performista, lo cual contradice uno de los rasgos esenciales del mito, su falta de expresividad, lo que ha sido expresado por Franz a propósito de la capital chilena: «Santiago el imbunche, con los esfínteres de su expresividad cosidos» (34).

El Imbunche funciona en Ygdrasil, en un primer nivel, como una marca, una etiqueta que sólo presta un significante, en principio carente de un contenido referencial. No obstante, con el transcurrir del relato el nombre se va completando con el cuerpo de diversas figuras que tienen otras denominaciones, pero que sí son verdaderos imbunches: el Círculo Doctrinario, la Horda Odínica, los lautaros, los navegantes de la Chrysler y, finalmente, la protagonista Mariana, quien es imbunchada en el desenlace de la novela. Pero, antes de hablar de ellos, nos referiremos al personaje que abre la narración, «el traspuesto», en tanto condición de posibilidad de los futuros imbunches. Es éste un «hombre agónico con su alma desplazada», que ha sido encontrado en el desierto de Sonora y que aúlla de dolor, debido a que sufre «una malformación difícil de explicar [...] Su existencia se encuentra traslapada entre su propio cuerpo, un cactus, una roca y una rata» $(9)^{10}$. Más adelante sabemos que tal segmentación ha sido posible gracias a una tecnología experimental, el Empalme Rodríguez, que permite «ensamblar un tubo

8 Uno podría preguntarse cuál es el sentido de tanto determinismo, más todavía si se considera que la única salida es una suerte de apocalipsis purificador que permitiría un nuevo inicio: «la destrucción que posibilite una eventual refundación» (56).

9 Es posible elucubrar que mientras para Donoso la sexualidad eventualmente podría representar un medio de liberación, o al menos de desterritorialización, como ocurre con el personaje de la Manuela en El lugar sin límites, para Baradit, más cercano en esto a Foucault, se trata de una de las técnicas de construcción de la subjetividad y, por lo tanto, de sujeción. Ello permite explicar la violencia sexual constante en Ygdrasil, lo cual la inscribiría en una importante línea narrativa desarrollada durante la segunda mitad del siglo XX que, tomando elementos de la pornografía, pone en escena, a través de la representación de intercambios sexuales sadomasoquistas, las relaciones de dominación, ya sean económicas o políticas, de lo cual son ejemplo los relatos de La máquina blanda de William Burroughs y, en el ámbito latinoamericano, el perturbador El fiord, de Osvaldo Lamborghini.

10 La descripción completa es: «un hombre pintado de azul se arrastra dolorosamente por el centro geométrico del desierto de Sonora, arañando la tierra con sus gemidos. Parece el espíritu moribundo del desierto, saliendo a jirones por la boca del desgraciado en forma de cuchillos kirlian y frecuencias electrónicas desgarradoras. Lloran todos los médiums en ochocientos kilómetros a la redonda, pues dondequiera que miren se les aparece el rostro desfigurado del doliente. Los aullidos del hombre pulsan como una inflamación los escáneres; son rítmicos a la manera de un código o una serie matemática, espasmos binarios de 
al costado de la Gruta de las Almas para desviarlas, por ese empalme, hacia una cadena de producción industrial donde [...] [son] encarnadas una a una en procesadores de última generación» (122). Esto significa, se dice, "la esclavitud digital para miles de almas» (123).

La división del alma del traspuesto tiene como telón de fondo la mutilación de cientos de cuerpos humanos y de animales que pasan a formar parte de maquinarias y de redes de transmisión de datos, y que se mencionan a cada momento en la novela, entregándose, no obstante, sólo rápidas explicaciones, en una suerte de procedimiento de anti extrañamiento. Así por ejemplo, se dice que la subcarpeta «Prototipos»: «Estaba repleta de mecanismos y aparatos que incluían humanos vivos insertos en sus formas, los que compartían sus funciones neurobiológicas y eran penetrados por organismos electrónicos a través de ojos, oídos y columna vertebral» (120). La brigada Ragnarok es otra muestra de lo mismo: cuatro hombres "puros», entrenados para mantenerse conscientes durante el sueño, se suicidan para reencarnarse en chamán-umbral y así poder viajar por la red de acupuntura terrestre y encontrar información sobre el Empalme Rodríguez, con lo cual sus almas se pierden definitivamente (138). La separación de los cuerpos en partes es también lo que ve Mariana cuando se está preparando la ofensiva contra el Directorio: "Cuerpos medio mutilados, con sus nervaduras deshilachadas, entraban en una fina maquinaria procesadora: tubos, fibras y sondas a través de ojos, oídos, boca. Doce cuerpos empalados en tubos a través de médulas espinales convergían en un tronco erizado de fibras conductoras y puntas disipadoras» (228).

De este modo, el traspuesto y la tecnología que lo permite representan una etapa inicial, necesaria para la posterior construcción de subjetividades imbunchadas: el sujeto fragmentado, que es condición de posibilidad de los verdaderos imbunches que irán proliferando a través del acontecer. Es decir, para que se pueda producir el imbunche se requiere, primero, que los seres sean divididos en partes, que sus órganos sean mutilados e incluso que se produzca la separación de cuerpo y alma ${ }^{11}$. Como dice Franz respecto de la capital chilena, el corte también es una forma de imbunchización: «La ciudad truncada, con los muñones de sus alas cortadas, de sus sueños podados» (34).

La fase inicial de la separación es seguida de un segundo momento de reunión, en el cual aparecen seres simbióticos, que actúan unidos bajo el mismo principio constructivo que utiliza a seres humanos como partes.

Ya en la descripción de dos de los principales espacios de la novela — la Chrysler (la corporación transnacional que se dedica al transporte de datos en la red) ${ }^{12}$ y el Ygdrasil (el árbol luciferino que permitirá el advenimiento de un Mesías informático que vencerá

dolor digital» (8). En otro trabajo, explicamos la insistencia en el dolor como una forma de oponerse a la descorporeización propia de las utopías informáticas (Areco).

11 Profundizamos en esto en el artículo recién mencionado.

12 Económica y políticamente, la Chrysler es una corporación global dedicada al transporte ciberespacial de datos, convertida en Estado-nación: «la empresa se volvió tan monstruosamente grande que negoció la compra de una extensa superficie de aguas internacionales entre el golfo de México y África. Con los años, una enorme costra metálica se fue asentando en el fondo del Atlántico, con millones de habitantes distribuidos en decenas de secciones productivas. Cuando la primera generación de personas nacidas dentro de las instalaciones hubo alcanzado la mayoría de edad, la Chrysler redactó una Constitución, entregó cartas de nacionalidad y pidió autorización para entrar en la ONU como Estado soberano» (78). 
al dios agónico $)^{13}$ - , aparece una estructura de este tipo, en que los hombres se constituyen como piezas, en este caso de transmisión de información:

La Chrysler es básicamente una costra flotante con un agujero en el medio. A través de ese agujero emerge el Ygdrasil desde sus asentamientos en el suelo marino. Es una anémona monstruosa que se eleva envuelta en nieblas. No toca los bordes del agujero en la Chrysler, se conecta a ella a través de cuatro seres humanos dispuestos en cruz. Sus cráneos están soldados a la estructura del árbol, y sus piernas entran en la Chrysler [...]. Torrentes de datos entran y salen a través de los vivientes, que oran día y noche, estimulados químicamente para sostenerse en un sartori permanente. Eso aumenta su conductividad (224).

No obstante, un mejor ejemplo para los efectos de este análisis son los seres simbióticos, pues en ellos se perciben los procedimientos de reunión e imbunchización combinados con una misma finalidad de sujeción. Así ocurre con el llamado Círculo Doctrinario - formado por niños, mujeres y ancianos, cuatro de cada uno, cuya finalidad es interpretar el libro sagrado del culto del Imbunche-, que es descrito como una entidad asociada, que al mismo tiempo cuenta con los rasgos principales de la imbunchización, que son la clausura de la vista y la costura: «A todos se les había arrancado los ojos y en su lugar tenían bolas de acero con cadenas soldadas a ellas que los unían entre sí en una ronda monstruosa. Las manos de los niños estaban cosidas a sus pechos, y todos andaban desnudos» (80).

El que no se trate de una mera costura, sino de ojos que están clausurados con bolas de acero y cadenas, realza la importancia de la noción de esclavitud en la novela. Pero, más importante que lo anterior nos parece el hecho de que la cadena que ata a los sujetos se conecte a través de los ojos, pues ello deja en evidencia la importancia de lo visual en el proceso de esclavización. Así, gracias a la figura del Círculo Doctrinario se puede afirmar el lugar central que, dentro del imaginario de Ygdrasil, tiene el sentido de la vista y su clausura. Como veremos a continuación, en la novela proliferan los modos de terminar con la vista, siendo el más importante de ellos la conexión a la red (no obstante, también es posible plantear su relación con las artes visuales, a lo que nos referiremos hacia el final del artículo).

Por otra parte, la Horda Odínica — «elite guerrera» (75) y «guardia del templo» (180) de la Sección 14- nos permite mostrar un tipo de entidades simbióticas imbunchadas, en las cuales el enceguecimiento se presenta en términos de conexión informática y cyborización ${ }^{14}$. Es ésta una entidad doblemente articulada: «compuesta por doce hombres con cerebro de delfín y extraordinarias capacidades psíquicas [...] Inmersos

13 Algunas descripciones del árbol: «El Ygdrasil es una estructura desaforada y monstruosa [...] Contiene componentes extraordinariamente variados: La miscelánea incluye a bandadas de golondrinas clavadas vivas a placas de circuitería [...] Catedrales románicas y arena de Kalahari [...] Pabellones llenos de ancianos entonan un mantra para mantener vibrando delgadas láminas de cobre cargadas de recuerdos sintéticos [...]; pilares huecos, llenos de niños en coma, conducen los campos de información estática [...] El Ygdrasil es una colmena fabricada por abejas esquizofrénicas. Es un constructo abominable que ofende la vista de Dios» (207-209).

14 Por motivos de extensión, en este trabajo no profundizamos en la noción de cyborg, otra de las modalidades importantes de representación de subjetividades en las novelas que analizamos. No obstante, nos parece que el «organismo cibernético», que ha generado una festiva defensa de la hibridez en el «Manifiesto cyborg» de Donna Haraway, es una forma de subjetividad intersticial, que pone en cuestión los límites entre lo natural y lo artificial, entre el ser humano y la tecnología y que vuelve porosos los conceptos de sujeto y de identidad. Ello se debe a que el hombre intervenido por implantes es una entidad intermedia entre el robot (o el androide) y el ser humano. 
en los cuerpos inertes de doce 〈tontos〉 - hombres sin corteza cerebral producidos con fines médicos- permanecían en estado de coma dentro de nichos ubicados bajo la losa del templo» $(75)^{15}$. La Horda controla telepáticamente a los «tontos», destinados al combate, quienes son representados como cyborgs - por ejemplo, llevan en la espalda una espada de cartílago cuya funda es la columna vertebral- (231-2). Pero si consideramos su "preparación", se hace evidente su carácter de imbunches y el hecho de que es la conexión el procedimiento principal de clausura: «les cosían todos los orificios del cuerpo. Los ojos eran vaciados y las cuencas alojaban hardware que sobresalía de las órbitas como cuernos sensoriales, conectados al sistema neurovegetativo a través de los nervios ópticos» (231).

Saltándonos una gran cantidad de otras mutilaciones ${ }^{16}$ y cyborizaciones ${ }^{17}$, llegamos a los navegantes de la Sección 14, quienes han nacido en el complejo industrial y realizan un trabajo tan extenuante que mueren en promedio a los 35 años, sin posibilidad de escapar. Los navegantes son, al igual que los tontos, cyborg-imbunches, cuyos sentidos han sido clausurados por los requerimientos de su labor en el sistema informático: «Seis horas diarias pasaban los operarios en el trance extático de la navegación y la mescalina, insertos como piezas vivas dentro del sistema de conectividad de la Chrysler» (77). En este caso, es la conexión a la red la que es descrita como una imbunchización, pues si bien ya no se trata de una clausura materialmente operada en los órganos de los sentidos - la costura característica del imbunche-, el resultado provocado por la inoculación de droga es el mismo, anulación de los sentidos y esclavización:

Todas las mañanas un ejército de operarios entraba en los galpones y conectaba sus cabezas a hubs de navegación inmensos, similares a grandes bloques llenos de agujeros similares a anos mecánicos que se cerraban fijando sus cuellos. Una aguja hipodérmica se hundía en la frente de cada trabajador y la iluminación comenzaba: el químico corría por las venas de la máquina y entraba directamente en la hipófisis de los obreros. Luego sincronizaban sus encefalogramas con un mantra digital que actuaba como umbral de entrada al gran océano de datos, y se sumergían en la enorme ameba que los abrazaba con su matemática vertiginosa (77).

Así, a partir del Imbunche, cuyo nombre ha dado la clave para descubrir el proceso de imbunchización al que son sometidos otros personajes del relato, hemos llegado a los navegantes de la Chrysler, suerte de imbunches químicos conectados a redes de transmisión de datos. Si queremos ahora abordar a Mariana, la última imbunche de la novela, debemos decir antes algo sobre las esclavas sexuales llamadas "perras», «un producto artesanal típico de los suburbios de Santiago de Chile» (43), que también son generadas mediante técnicas de imbunchización, aunque en este caso el mito es sometido a ciertas actualizaciones, al agregársele dos modalidades de la explotación económica propias del capitalismo tardío: la industria cárnica y la comercialización de órganos. En efecto, la

«El Imbunche los mantenía secuestrados bajo la curiosa figura del Voto de Prisión Sagrada» (75).

16 Por ejemplo, el hombre llave que permite entrar a la Intranet de la Chrysler: «Un gran perno atravesaba sus muñecas, fijado con una enorme tuerca de bronce [...] Evidentes marcas de tortura cruzaban su cuerpo; le faltaban las orejas, la nariz, los dedos de los pies y los genitales» (198).

17 Es el caso de los lautaros de la Chrysler: guerreros gigantes de dos metros diez de altura, con musculatura reforzada, genitales extirpados, garras de acero y rostro cubierto de moscas. "Cada lautaro tenía un implante electrónico en la nuca para ser controlado a distancia; así se le estimulaba el principio de la ira» (236). 
operación parte con el rapto y la mutilación a los que ya nos hemos referido, ligados a la producción industrial de alimentos, y continúa con tecnologías que recuerdan al electroshock, para terminar con las empleadas en los frigoríficos:

El procedimiento es bastante sencillo. Secuestran a mujeres, les extraen las cuerdas vocales, las córneas, la médula espinal, el riñón y todo lo aprovechable para el mercado de órganos. Luego les fríen el cerebro mediante un proceso muy lento y doloroso: inducen pavor límite a través de punciones directas en la masa encefálica, inundan la corteza con pulsos eléctricos, provocan el suicidio químico del yo [...].

Es un proceso barato. Y para abaratarlo aun más disminuyen los costos de almacenamiento y transporte amputándoles brazos y piernas [...]. Luego las cuelgan en bolsas a unos rieles frigoríficos que mantienen sus metabolismos funcionando al mínimo, alimentándolas con suero directamente a la vena (43-4).

Todo el proceso, desde el rapto y la mutilación hasta la mudez y la tortura, es similar al de la imbunchización, con los agregados modernos y posmodernos con que Baradit condimenta su narración. La diferencia es que aquí la motivación no importa (por ejemplo, la envidia en Edwards Bello); sólo la conversión de la mujer secuestrada en mercancía.

Mariana, cuya madre ha sido una perra al servicio de su padre, logra escapar a este destino luego de asesinar a su progenitor, quien la ha violado y la ha explotado durante cuatro años, huyendo de Chile a México, convirtiéndose primero en una sicaria - adicta a una droga a base de maíz- que sólo asesina a hombres, y luego siendo «redimida» por el gobierno, que la obliga a infiltrarse en el sistema informático del Banco de México para conseguir información clasificada. No obstante su aparente escape, a través de toda la novela se manifiesta su miedo de convertirse en perra, lo que se cumple al final cuando es instalada como «la joya del Ygdrasil», una pieza fundamental del árbol cosmogónico, mediante desmembramiento e imbunchización: «Allí, suspendida, le arrancaron piernas y brazos, la cauterizaron con hierros al rojo vivo y la incrustaron con ganchos de acero al mecanismo que colgaba en el centro del útero. Incrustada como una joya. La joya del Ygdrasil. / Luego le extrajeron los ojos y le hundieron terminales de datos en los nervios ópticos» $(265)^{18}$.

Consideremos ahora el polo activo del proceso de imbunchización, los «brujos» que lo ponen en práctica para obtener servidores, o más bien esclavos, a cuya luz podemos entender mejor la figura del líder sindical de la Chrysler, quien aparece como una suerte de chivato, siguiendo el nombre del monstruo de Lastarria, en tanto responsable de una parte importante de la producción de imbunches: la imbunchización del Círculo Doctrinario, de la Horda Odínica y de los tontos. Pero el Imbunche, falso profeta, es también

18 Mariana, el imbunche final de la novela, también ha sido sometida al primer estadio de la conversión que, como veíamos, es la mutilación. Así, cuando su padre la viola, siente que se fragmenta: «Yo estaba desierta, vacía, desmembrada. Mi alma había volado a otro lugar y mis ojos estaban clavados en un nudo de madera del techo» (47). La penetración violenta es entonces una posibilidad de la mutilación, lo cual se comprueba un poco más adelante, cuando es atrapada en el Banco de México y sometida a un nuevo desmembramiento por los ejecutivos de éste: «Entonces la crucificaron a la mesa./ Le extrajeron costillas y dedos. Alinearon todo cuidadosamente en torno de ella como un gran mandala de restos humanos [...]./ De pronto el ritual pareció llegar a su fin. Solo el jadeo mínimo de la mujer anunciaba que esos despojos desordenados, sanguinolentos, habían sido un ser humano. Entonces entró ese otro hombre. Con una daga le abrió lentamente el costado, copuló con ella a través de la herida y eyaculó en su interior» (29). En la nota 9, hemos intentado explicar el sentido de la recurrencia al relato pornográfico en la novela. 
un falso brujo, no sólo porque no es lo que su nombre indica, ni porque engañe a sus fieles, sino porque él mismo no es más que una pieza que otros mucho más poderosos que él manejan. Así, quienes comandan los procesos de imbunchización son, en primer lugar, los miembros del Directorio de la Chrysler, generadores de los imbunches (que son los navegantes) y, en segundo lugar, los misteriosos Perfectos, una especie de secta milenarista que propugna el nacimiento de un Mesías informático: «la unión de todos los seres humanos en una red consciente y el advenimiento del Mesías, un metahombre hecho de todos los hombres» (206). Lo anterior es hecho posible por la Red: "Los grupos económicos mundiales fomentan el desarrollo de internet. Tras ellos, los Perfectos buscan reproducir a escala planetaria la estructura neuronal de un santo» (205). De ellos apenas se entregan explicaciones, casi todas en los epígrafes, pero podemos deducir que son los productores del Imbunche, de la Sección 14 como granja de cultivo de almas de alta calidad y de Mariana, la «joya» imbunchada al servicio del árbol cosmogónico, el Ygdrasil.

La sección 14 es parte del proyecto para despertar a la Chrysler. El Empalme Rodríguez proveerá de almas a los computadores del Ygdrasil para que despierten a la Chrysler y la hagan extenderse por las redes de la Tierra. Pero no la proveerá de almas cualquiera, sino de aquellas que hierven de fervor religioso [...]. La Sección 14 es una granja de cultivo de esas almas especiales. El fanatismo es una característica que se ha estimulado, no una casualidad [...] La Sección 14 proveerá de almas con elevados índices de éxtasis religioso para los computadores del Ygdrasil. El levantamiento en armas también está previsto. La euforia y la muerte de los combatientes imbuidos de espíritu santo es la que conferirá a sus almas los mejores niveles de calidad. La batalla de mañana es sólo la culminación de un largo y armonioso proceso de cultivo. La cosecha (222).

De este modo, contra la imagen inicial que de él nos hacemos, el líder del sindicato de la Sección 14 es, por lo menos en cuanto esclavo, un imbunche verdadero. De ahí que en diferentes momentos se corte y se mutile los órganos de los sentidos. Así, en medio de la planificación del combate contra el Directorio, «se había hecho extraer la pared que separaba las fosas nasales» (190) y, a pocos minutos de iniciar la ofensiva, «se había amputado las orejas» (230). Pero el Imbunche no sólo se mutila, también se adorna: "se había hecho soldar a cada vértebra largas puntas metálicas que exageraban sus gestos y movimientos. De la piel de sus omóplatos entraban y salían alambres en diseños geométricos; erosiones y cortes profundos en sus nalgas se prolongaban hacia los muslos. Se había vestido de gala para la ocasión» $(182)^{19}$. Su performance corporal incluye además la alta tecnología, con lo que nuevamente se insiste en la importancia de lo visual: «cargaba un monocomputador adosado a su ojo derecho»(219). De ahí también que sea representado como una suerte de artista de vanguardia alienado ${ }^{20}$, aquel que, sin darse cuenta, es un esclavo inconsciente, al modo en que Virilio juzga al artista australiano Stelarc (cuyos trabajos se asemejan a los del Imbunche), al servicio de un proyecto de colonización del cuerpo humano indefenso por la biotecnología y la informática. Su

19 Más adelante: «El profeta [...] mostraba un cráneo afeitado, lleno de pequeños tatuajes y trozos de alambre que entraban y salían de su piel, elevando sus diseños más de un metro sobre su cabeza» (230). Antes, se ha hecho mención explícita al arte: «el Imbunche ejecutaba para sus fieles un ritual coprofílico basado en el concepto de alimentarse de Dios y comer su carne [...]. La misa, una especie de acción de arte, culminaba apoteósicamente con el Imbunche eyaculando sangre en un vaso de metal» (192).

20 Un mayor desarrollo de esteas ideas en Areco. 
carácter de esclavo ${ }^{21}$ se revela cuando, una vez que ha cumplido su papel y ha dejado de ser útil, desaparece junto con la Sección 14. Así, el artista de vanguardia alienado que es el líder religioso aparece en una segunda lectura como un imbunche, en tanto desconectado de la realidad material, ciego, sordo y mudo frente a los requerimientos del cuerpo y del dolor, y entregado a la esclavitud a la que la digitalización nos envía o a la endocolonización (Virilio) ${ }^{22}$.

Vemos así cómo en Ygdrasil Baradit continúa una tradición de la literatura chilena, al utilizar el mito del imbunche como clave de representación de la identidad nacional, pero al mismo tiempo la altera, pues ya no se trata de la crítica desde la élite de rasgos fijos (como ocurre con Edwards Bello y Franz), sino de la condición de un sujeto posmoderno fragmentado y conectado a redes informáticas globales, al servicio de poderes desconocidos y a merced de una supuesta utopía tecnológica, el cual es representado, entre otros, por las figuras de la mujer utilizada como carne, del político corrupto que colabora pensando que así logra su propio beneficio y del artista de vanguardia alienado, obnubilado por la tecnología.

\section{REFERENCIAS}

Areco, Macarena. «Más allá del sujeto fragmentado: las desventuras de la identidad en Ygdrasil de Jorge Baradit». Revista Iberoamericana 232-233 (2010). Revista electrónica.

Baradit, Jorge. Ygdrasil. Buenos Aires: Ediciones B, 2005. Medio impreso.

Bull, Malcolm. La teoría del apocalipsis y los fines del mundo. México: Fondo de Cultura Económica, 1998. Medio impreso.

Donoso, José. El obsceno pájaro de la noche. Prólogo, cronología y bibliografía Hugo Achugar. Caracas: Biblioteca Ayacucho, 1990. Medio impreso.

21 «Proyecto — dice Virilio- del que nuestro australiano no es, evidentemente, el instigador sino más bien la víctima, una víctima que consiente, como lo hace tan a menudo el ser pervertido por su amo" (124). Sólo que el Imbunche es un esclavo que no tiene conciencia de serlo, pues le ha tocado, por lo menos durante un tiempo, un lugar privilegiado en la división internacional del trabajo, como líder religioso o artista de vanguardia. El Gran Chamán de la Tierra, El Tangata Manu, le señala cuál es su lugar: «Es verdad que estás en medio de algo que no puedes imaginar, pero no eres un obstáculo, sino apenas una hormiga robando granos de azúcar» (165).

22 A su definición como líder religioso y artista, hay que sumarle su carácter más evidente de líder sindical. La mezcla de arte, religión y política permite situar al Imbunche y a su culto en una esfera premoderna, más cercana a la Edad Media, si seguimos a Weber en que lo propio de la modernidad cultural es la distinción de estas tres esferas. A ello hay que agregar que él se encuentra en la Sección 14 de la Chrysler, una empresa-Estado global en la que se practica un sistema esclavista, y que esa sección es la de los pilotos que navegan en el ciberespacio. En este sentido, lo que Ygdrasil está anunciando es el advenimiento de una suerte de neomedioevo tecnológico (lo que, por lo demás, no es novedoso en la ciencia ficción universal, como puede constatarse en las Fundaciones de Asimov y en Dune de Frank Herbert). Otra novela chilena del período, La segunda enciclopedia de Tlön de Sergio Meier, lo dice transparentemente en el primer párrafo de su Prefacio «Infinitos Universos de Realidad Virtual fueron creados a finales del siglo XX: las imágenes de síntesis se perfeccionaron dentro de la Red, y doce Corporaciones llevaron a la humanidad a una nueva Edad Media, solo que esta vez, informática. / El orden político y social se vio radicalmente alterado por el nacimiento de un sistema de feudos, que transformó a la mayoría en vasallos de una realidad artificial que consideraban como legítima» (17). 
Edwards Bello, Joaquín. Mitópolis. Santiago: Nascimento, 1973. Medio impreso.

Franz, Carlos. La muralla enterrada. Bogotá: Planeta, 2001. Medio impreso.

Haraway, Donna. «Manifiesto Cyborg. Ciencia, Tecnología y Feminismo Socialista Finales del S. XX». Manifiesto Cyborg. Sitio web. Fecha de ingreso: 20 de octubre de 2009.

James, Edward. Science Fiction in the Twentieth Century. Oxford: Oxford University Press, 1994. Medio impreso.

Lastarria, José Victorino. Don Guillermo. Prólogo de Luis Íñigo Madrigal. Santiago: Nascimento, 1972. Medio impreso.

Lockhurst, Roger. Science Fiction. Cambridge-Malden: Polity Press, 2005. Medio impreso.

Montecino, Sonia. Mitos de Chile. Diccionario de seres, magias y encantos. Santiago: Sudamericana, 2003. Medio impreso.

Robert, Adam. Science Fiction. London: Routledge, 2000. Medio impreso.

Virilio, Paul. El arte del motor: aceleración y realidad virtual. Buenos Aires: Manantial, 2003. Medio impreso.

Recepción: 20 de enero de 2011

Aceptación: 4 de marzo de 2011 